\title{
QUER DANÇAR COMIGO? A PESSOA COM DEFICIÊNCIA NA CENA CONTEMPORÂNEA TUCURUIENSE ATRAVÉS DA EXPERIMENTAÇÃO DO MOVIMENTO
}

\author{
Roseane Monteiro dos Santos \\ UEPA
}

\section{Resumo}

A temática abordada neste projeto de criação/ experimentação ora apresentada reflete um interesse em contribuir na discussão que tem como alicerce o contexto dos pressupostos teóricos de Ann Cooper Albright, a qual discute a inserção das pessoas com deficiência física na cena artística, propondo ao mundo a visualização dessas pessoas enquanto efetivamente artistas da cena, além da chamada dança inclusiva. Objetivo: Investigar através da experimentação, movimentos artísticoscultu-rais propostos por pessoas com e sem deficiência para a cena contemporânea tucuruiense. Metodologia: Baseia-se em uma pesquisa-ação. A amostra foi constituída de 05 (cinco) pessoas, sendo estas: 02 (duas) com deficiência física, 1 (uma) de baixa visão e 02 (duas) sem deficiência. Para coleta e análise dos dados usamos o diário de campo, observação, grupo focal e laboratórios de criação. Resultados: As investigações resultaram em descobertas e ressignificações dos corpossujeitos envolvidos, com superações corporais e psicológicas com rica troca de ações. Conclusão: As experimentações foram além do esperado, mas foi constatado que a sociedade e os próprios artistas em Tucuruí têm dificuldade em ver além da chamada dança inclusiva.

\section{Palavras-chave:}

Pessoa com deficiência; Dança contemporânea; Movimento; Intérprete-criador.

\section{INTRODUÇÃO}

A temática abordada neste projeto de criação/ experimentação ora apresentada reflete um interesse em contribuir na discussão que tem como alicerce o contexto dos pressupostos teóricos de Ann Cooper Albright, a qual discute a inserção das pessoas com deficiência física na

\section{Abstract}

The theme discussed in this creation / experimentation project presented here, reflects an interest in contributing to the discussion that builds on the context of the theoretical assumptions of Ann Cooper Albright which discusses the insertion of people with physical disabilities into the art scene, proposing to the world the visualization of these people as effectively performers of the scene, in addition to the so-called inclusive dance.Objective: To investigate, through experimentation, artisticcultural movements proposed by people with and without disabilities for the contemporary scene in Tucuruí. Methodology: It was based on an action research. The sample consisted of 05 (five) persons, of whom: 02 (two) with physical disabilities, 1 (one) of low vision and 02 (two) without disability. For data collection and analysis, we used the field diary, observation, focus group and breeding laboratories. Results: The investigations resulted in discoveries and re-significances of the involved subjects-bodies, with corporal and psychological surpasses with rich exchange of actions. Conclusion:The experiments were more than expected, but it was found that society and the artists themselves in Tucurui have difficulty seeing beyond the so-called inclusive dance.

Keywords:

Person with disabilities; Contemporary dance; Movement; Interpreter-creator.

cena artística, propondo ao mundo a visualização que existe nessa inserção uma rica troca de criar e compartilhar movimentos entre pessoas com e sem deficiência, além da chamada dança inclusiva.

A ideia de uma proposta investigativa de movimentos, pautada em uma ressignificação, onde a pessoa com deficiência de qualquer 
característica deixa de ser somente uma repetidora dos movimentos propostos e passa para um trabalho de intérprete-criadora é o que este projeto se lançou.

O projeto ainda se respalda nos pressupostos teóricos de Rossi e Munster (2013); Koudela (2013); Belém (2011); Rocha (2010). E a partir desses pressupostos, somamos o questionamento que foi feito pelo elenco, composto de pessoas com e sem deficiência, ao público nas ruas de Tucuruí: Quer dançar comigo? E assim, tivemos a oportunidade de verificar as reações deste público ao perceberem que existem também artistas da dança com deficiência.

Fortalecendo esta discussão, é interessante ressaltar que a dança contemporânea propõe olhares diferenciados quanto à estética, formas de criação e padrões inerentes à dança, direcionando os artistas deste contexto ao diferente, ao grotesco, deformado, não comum, resultando assim em ferramentas diferenciadas e ricas para criações, ampliando ferramentas e assim ampliando da mesma forma os resultados no que diz respeito à criação de movimentos que podem ser utilizados não só na cena artística, mas também no cotidiano do bailarino-artista-cidadão.

A partir desse ponto, a pessoa com deficiência tem seu espaço e deve participar das pesquisas que permeiam a dança não somente como artistas das discussões sobre inclusão ou questões de políticas públicas e sim como efetivamente artistas da cena com espaço, ação e acesso a essa cena.

Assimsendo, inserirocorpo-sujeitocomdeficiência na criação artística da cena contemporânea proporcionando momentos críticos-reflexivos, é abrir caminhos para o recriar, refazer, ressignificar e assim não vitimando, nem subestimando este corpo na cena em uma perspectiva contribuinte de novos resultados a pesquisadores que se lancem nessa área que ainda necessita destas pesquisas e de incentivos a essas.

Levar para a cena dançante contemporânea corpossujeitos com e sem deficiência para experimentar a metodologia teatral, através por sua vez da metodologia do foco e da improvisação, permitirá aos envolvidos a oportunização de suas ações criativas a partir da interiorização dos objetivos, com ênfase ao fazer artístico (KOUDELA, 2013).
Levar ainda para a cena contemporânea corpossujeitos com e sem deficiência e repletos de sentidos e significados, a partir de uma proposta de experimentação, de utilização da dançateatro, do contato-improvisação, auxiliando para o efetivo conhecimento de quem eu sou e o que posso fazer realmente com meu corpo de forma a perceber, ouvir e criar contribuirá para investigações necessárias no fazer artístico da cena tucuruiense (BELÉM, 2011).

Esta pesquisa foi resultado do concurso de bolsa de criação, experimentação, pesquisa e divulgação artística da Fundação Cultural do Estado do Pará Tancredo Neves, por meio do edital n) 1/2015 e teve como produto final um espetáculo com nossa MultiCorpo Cia de Dança, a qual trabalha com corpos-sujeitos diferenciados como pessoas com deficiência, gordos, magros, travestidos para busca de novos olhares ao movimento dançante.

O objetivo geral foi investigar através da experimentação, movimentos artísticos-culturais propostos por pessoas com e sem deficiência para acena contemporânea tucuruiense. E seus objetivos específicos: oportunizar a criação/experimentação/ compartilhamento entre pessoas com e sem deficiência; promover discussão entre o elenco do projeto a respeito do fazer artístico em uma perspectiva reflexiva dos contextos que permeiam este fazer; oportunizar uma construção particular de criação/experimentação artísticas dos envolvidos para efetiva ferramenta aos movimentos artísticos; verificar a reação do público nas ruas de Tucuruí ao serem questionados pelo elenco: Quer dançar comigo?; instigar as pessoas com e sem deficiência a pesquisarem juntas na mesma cena, propostas de atuações expressivas; socializar os resultados desse projeto de criação/experimentação em espaços públicos para difusão da arte e dos incentivos públicos a ela proporcionados; proporcionar ganhos financeiros aos prestadores locais de serviço na área artístico-cultural, ação relevante no interior do estado do Pará.

\section{JUSTIFICATIVA}

As concepções sobre corpo são fortemente influenciadas pelo momento histórico do ser humano, alimentada por questões socioculturais, filosóficas, educacionais, artísticas onde o encontramos em um estado pleno de significados através do viés tempo. Procurar entender as 
concepções acerca do corpo não é tarefa simples, visto que estas concepções estão em constante movimento e sendo ressignificadas até hoje em nosso século XXI.

Nosso corpo é dotado de movimento mesmo quando estagnado, mesmo quando aparentemente preso em uma cadeira de rodas, limitado em condições físicas, psíquicas ou culturais e esse movimento se dá por meio da percepção do interno e do externo do nosso corpo. As variações biológicas, a construção de nosso pensamento, nossas percepções no tempo/espaço resultam em construções de movimentos além dos visualizados em um corpo sem deficiência (TURSI, 2012).

Em se tratando de corpo com deficiência visualizamos as mesmas influências somadas ao fato de, mesmo com a ciência avançando, ainda necessitamos de mais pesquisas sobre a discussão dos sentidos e significados desse corpo-sujeito. Não nos atentamos nesta pesquisa a uma discussão de inclusão ou políticas públicas, e sim a um fazer artístico necessário à pessoa com deficiência.

Quando falamos do corpo com deficiência na área artística na interface dançade-ficiência, os espaços para trabalharmos nesta área crescem, os estudos avançam, porém, as publicações ainda são escassas no que diz respeito à profissionalização. São vistas pesquisas e atuações no que diz respeito a esta profissionalização que a dança direciona a corpos-sujeitos definidos e magros, com performances extremas e em uma concepção de beleza que ainda nos confunde, porém, para pessoas com deficiência enquanto efetivamente artistas, ou seja, em um mercado de trabalho, essas atuações são limitadas (PLÁ, 2013).

Verificamos, da mesma forma, que as manifestações sobre dança e a pessoa com deficiência são significativamente visíveis, todavia ainda em uma linha de bailarinos com deficiência que produzem performances visuais com suas muletas e cadeiras e na reprodução de movimento e pouco na linha do intérprete-criador como propõe a dança contemporânea (ROSSI, MUNSTER, 2013).

Leis que não contribuem e investimentos nacionais na área cultural escassos são exemplos para que apenas comecemos o diálogo da pessoa com deficiência enquanto artista além da visão da inclusão, sobre isso Plá (2013, p. 23), narra que “a arte aqui já leva a carga da deficiência antes mesmo de ser arte. Ela é utilizada primordialmente para transmitir mensagens de inclusão".

Somera (2008), por sua vez, relata que até mesmo os engajados no meio artístico têm dificuldades em se verem com tal e também de se verem como não amadores, já que a falta de incentivo nos próprios grupos nos quais são inseridos está presente. Sendo assim, verificamos que são muitos contextos que poderiam ser pesquisados nesse meio da dança através da pessoa com deficiência.

Necessitamos que estes contextos sejam pesquisados em um olhar que transcenda os conhecimentos pré-estabelecidos para que nos enriqueçamos com os resultados no fazer artístico. A respeito desse ponto, Albright, 1997, traduzida por Barbo e Dantas, 2009, p.3, fundamenta-nos.

\begin{abstract}
A interseção entre dança e a deficiência é um lugar extraordinariamente rico para explorar as construções sobrepostas da habilidade física do corpo, da subjetividade e da visibilidade cultural. Buscar o significado destas construções é fazer uma escavação arqueológica para dentro dos medos psíquicos que a deficiência cria. [...] Assistir a corpos deficientes dançando nos força a ver por meio de uma visão dupla, e nos ajuda a reconhecer que, mesmo que uma performance de dança seja baseada nas capacidades físicas do dançarino, ela não é limitada por ela.
\end{abstract}

Esta perspectiva nos faz pensar sobre os ricos resultados que podem ser causados a partir do processo de experimentação entre corpos com e sem deficiência. Esta relação abrangente nos faz pensar também que nós coreógrafos, diretores artísticos, atuantes do fazer cênico, podemos trilhar entre o fazer-dançar e o fazer-pensar em uma relação crítico-reflexiva, contribuindo nos aspectos sociais, culturais, educacionais dos cidadãos, remetendo-nos, dessa forma, a compreendermos a cena não só como um lócus artístico, mas também como um lócus social.

As vivências voluntárias que experimentei com as pessoas com deficiência mental na antiga Casa de Saúde Transitória em Belém, hoje Abrigo Lar de Ismael, mais a experiência dos corpos-sujeitos que dançaram minhas coreografias na APAE e na Associação Carajás da Pessoa com Deficiência, ambas as instituições no município de Tucuruí (PA), trouxeram-me uma percepção muito particular sobre os movimentos propostos a esses corpos que entravam na cena e apresentavam a mensagem. 
Vê-los não somente repetir estes movimentos a sua maneira, mas também interpretá-los de forma transcendente, preenchendo a cena com um corpo-sujeito dotado de sentidos e significados me instigou a buscar outros horizontes no fazer artístico, experimentando na cena tucuruiense a ação de intérpretes-criadores entre pessoas com e sem deficiência, a partir de ferramentas estudadas na área da dança, em especial da dança contemporânea.

Dessa forma, este projeto teve sua relevância por tratar de um contexto que necessita de incentivos para sua experimentação, ou seja, o da pessoa com deficiência e assim proporcionou resultados que puderam contribuir para a produção da cena, a partir de cada um dos envolvidos no referido projeto. $E$, para isso, buscou as questões sociais, culturais, educacionais, psicológicas que cada corpo-sujeito pudesse apresentar para assim, ressignificá-las e prepará-las para termos o resultado de um fazer artístico crítico--reflexivo.

Então, surgiu assim o projeto: Quer dançar comigo? A pessoa com deficiência na cena contemporânea tucuruiense através da experimentação do movimento que concorreu ao edital 2015 proposto pelo Governo do Estado do Pará, obtendo sua aprovação o que favoreceu o fomento da criação, da experimentação, da pesquisa e da divulgação da arte a qual estou envolvida em sua interface dançadeficiência, além dos benefícios significativos à área cultural, social, econômica e artística do município de Tucuruí.

\section{METODOLOGIA}

Esta pesquisa baseou-se em uma pesquisa-ação, ou seja, com enfoque qualitativo. A pesquisa-ação, segundo Thiollent (2007) caracteriza-se como um estudo teórico-prático, de modo que participantes e pesquisadores estejam envolvidos, onde todos têm sua participação planejada, o que pode proporcionar ao grupo pesquisado possíveis mudanças de atitude e/ou comportamentos de forma interativa.

A pesquisa aconteceu na MultiCorpo Cia de Dança idealizada e dirigida por mim há 11 anos e que procura trabalhar com corpos dançantes diferenciados como pessoas com deficiência, sem experiência em dança, travestis, enfim, fora do contexto tradicional. A Cia atua em Tucuruí (PA), município localizado a 457 km da capital Belém.
A amostra foi constituída de 05 (cinco) bailarinos com e sem deficiência, sendo estes: 02 (duas) com deficiência física que já tiveram a experiência de estar na cena, mas sem experiência de intérpretes-criadores, 1 (uma) de baixa visão que não teve nenhuma experiência na cena e 02 (duas) sem deficiência e com experiência na cena, inclusive no que diz respeito à ferramenta de intérpretes-criadores.

Baseada ainda por Rocha (2010) foram utilizados como instrumento de coleta e análise dos dados:

- Diário de Campo: para os registros em todos os encontros, das situações e ações dialógicas onde ocorreu o efetivo interesse do pesquisador e dos participantes diretos ou indiretos na pesquisa na ação escutada, falada registradas em vídeos.

- Observação Participante: na qual o pesquisador efetivamente participa do processo observando-o, agindo e registrando-o por completo. Esta etapa foi a ação da pesquisadora como intérprete-criadora.

- Grupo Focal: processo em que se oportuniza aos participantes lidar com as situações individuais e coletivas a fim de expor, criar, recriar, refletir, criticar para assim transformar as experiências no decorrer de todo o processo, incentivando-os a todo o momento. Nesta etapa foi aplicada uma entrevista aos envolvidos e registrada em vídeos.

- Laboratório de Criação: espaço onde foram realizados os laboratórios teórico-práticos de técnicas teatrais, dança contemporânea e contato-improvisação, os quais proporcionaram aos envolvidos as experiências e saberes necessários às produções criativas do projeto. Aqui também foram concretizadas a experimentação, interpretação, produção e discussão em um processo de análise dos movimentos que compuseram o produto final, ou seja, o espetáculo.

\section{RESULTADOS E DISCUSSÃO}

A temática abordada neste projeto de criação/ experimentação resultou no espetáculo de dança contemporânea: Quer dançar comigo?, de aproximadamente quarenta e cinco minutos proporcionado pela pluralidade da dança contemporânea, através da experimentação, da linguagem verbal e da improvisação em uma construção coletiva entre os atores da cena e dos bastidores, interligados pela vontade de gerar 


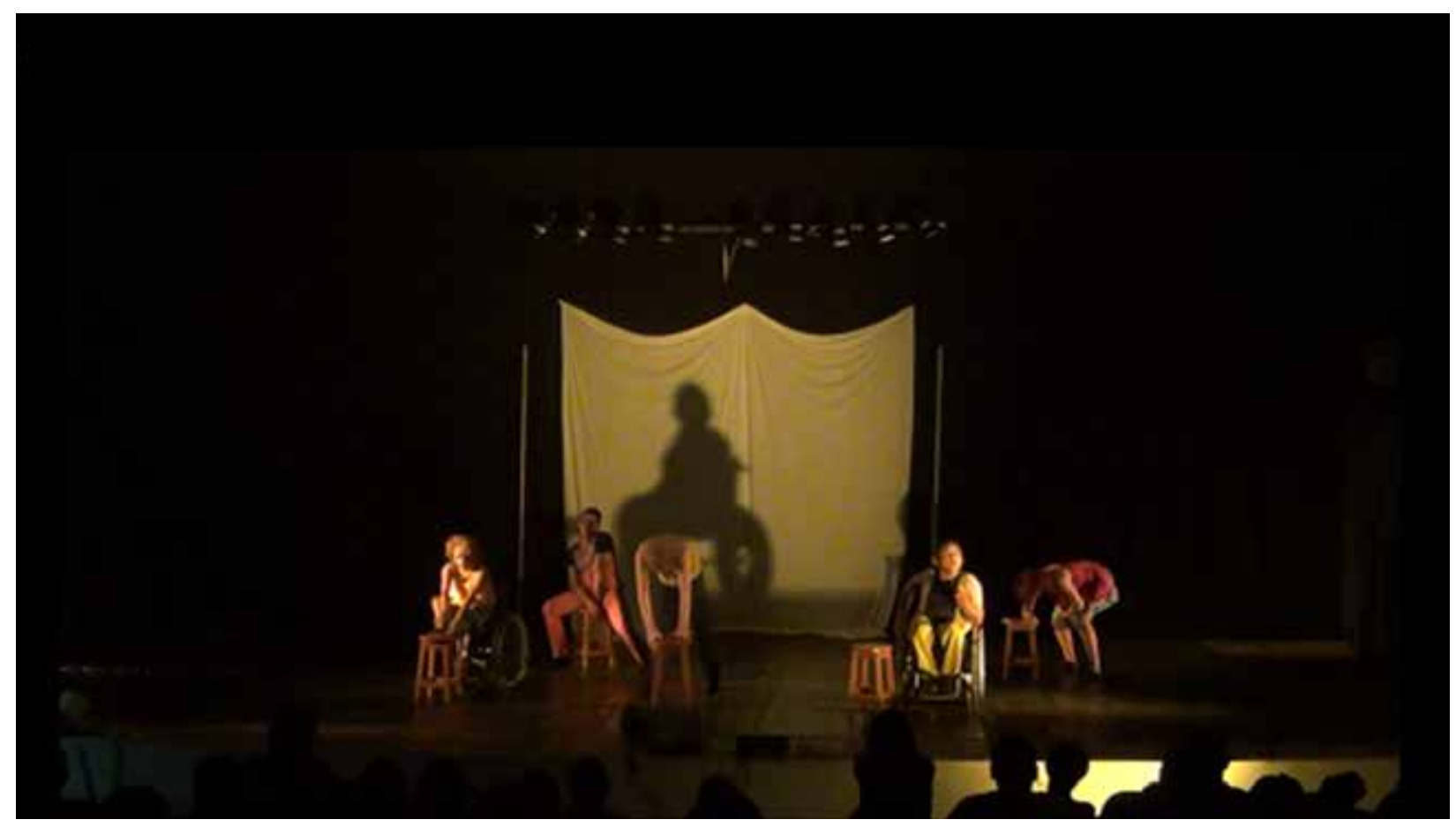

Figura 1 - Fotografia 1 - Cena de criação própria e improvisação. Fonte: Arquivo MultiCorpo Cia de Dança. Centro de Convenções de Tucuruí, 2015.

um produto que proporcionou ao público uma visão além do visto no cotidiano corporal com deficiência ou não.

A fotografia 1 registra a cena em que mais os bailarinos utilizaram-se de sua criação/ improvisação dentro do espetáculo. Essa criação foi diversa, rica, profunda, inesperada tanto das pessoas com deficiência quanto sem deficiência, na qual ideias e padrões foram ressignificadas. Todos os artistas envolvidos acreditaram em seu poder de criar e interpretar e para que esse resultado fosse positivo às metodologias que a dança contemporânea pode transitar, com sua sempre investigação, foram fundamentais.

Os laboratórios, as ferramentas do contatoimprovisação, os jogos teatrais, tudo foi constantemente utilizado e ressignificado a cada processo. Propor para cada participante sua investigação mais intrínseca diversa, utilizandose para isso do imaginário, da sensibilização e da inquietação, resultou em movimentos muito particulares, mas que puderam ser experimentados entre todos os participantes.

Corroborando com esse ponto, Rocha (2010, p. 56) em sua pesquisa com pessoas com deficiência visual, elaborou um quadro para utilização na criação e chamou de elementos estruturantes do processo de criação, no qual teve como resultado formas positivas de criar e ressignificar através do processo de sensibilização e instrumentalização do corpo-sujeito "não haveria outro jeito, senão tomar como fonte a suas respectivas maneiras de criar, sistematizar, lançar, dialogar e, acima de tudo, atuar".

A fotografia 2 registra o momento em que os bailarinos foram à campo captar ferramentas a partir da pergunta proposta pelo projeto: "Quer dançar comigo?", a qual foi levada à área externa dos envolvidos diretamente no espetáculo, chegando à feira municipal de Tucuruí. A pergunta era feita de forma aleatória a qualquer pessoa, sendo estas feirantes ou clientes destes, onde, nós da Cia MultiCorpo, bailarinos com ou sem deficiência, solicitávamos a autorização para registros e lançávamos a pergunta diretamente.

Mesmo com as chamadas discussões sociais acerca da pessoa com deficiência quanto à inclusão, aceitação entre outros, os resultados para esta pergunta foram os mais diversos e foram diretamente ligados se o bailarino tinha ou não a deficiência, então, os sem deficiência quando faziam a pergunta eram rapidamente respondidos e de forma prática, o seja, o entrevistado já se 


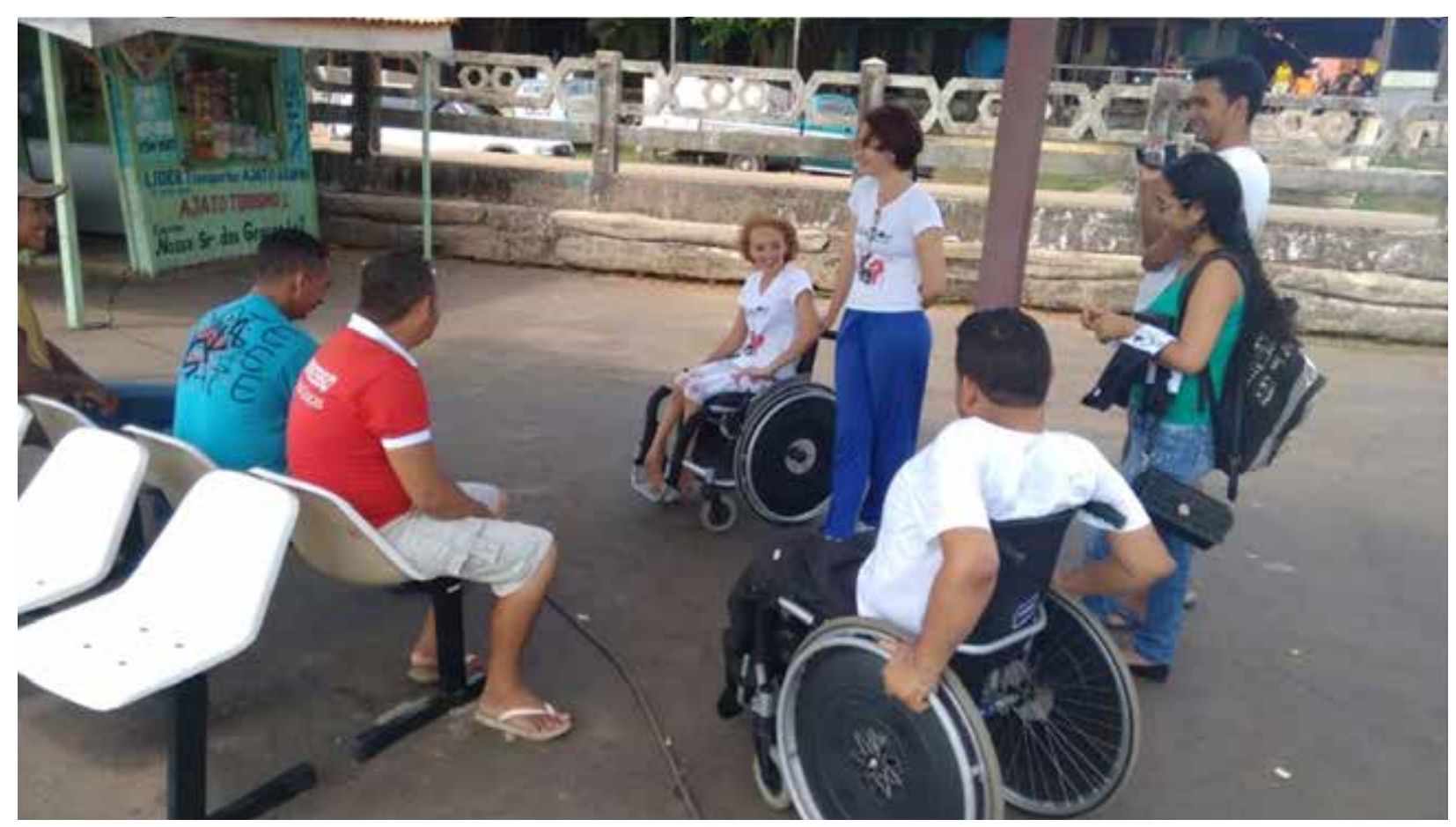

Figura 2 - Fotografia 2 - Momento do questionamento: Quer Dançar comigo? Fonte: Arquivo MultiCorpo Cia de Dança. Feira Municipal de Tucuruí, 2015.

propunha a dançar e geralmente a música que estava naturalmente sendo ouvida pela feira. Porém, quando quem fazia a pergunta eram os bailarinos com deficiência, principalmente os físicos e nos apresentávamos como bailarinos profissionais, os resultados eram de espanto, desconfiança quanto a acreditar que eles poderiam dançar e de maneira profissional. Algumas pessoas se propunham a dançar com eles, outras não.

Sobre isso, Teixeira (2010, p. 4) em uma pesquisa junto à Roda Viva Cia de Dança (bailarinos com e sem deficiência) fala que "[...] tornase incompreensível a não aceitação do corpo deficiente nos grupos tidos como tradicionais" e que mesmo com todos os discursos inclusivos em nosso século, as pessoas com deficiência têm dificuldades devido às imposições sociais e muito mais na questão artística-profissional.

Melhorias psicológicas, sociais, motoras e de autoestima foram verificadas no projeto através dos relatos dos participantes. A fotografia 3 registra um momento relevante para toda Cia e em especial ao bailarino Cícero Silva, no que diz respeito às questões emocionais e psicológicas, pois seu medo de sair da cadeira de rodas para experimentar movimentos no plano baixo, era aterrorizante. À princípio, quando a proposta foi lançada ao bailarino ele relutou bastante, porém no decorrer dos laboratórios ele foi adquirindo confiança, até que uma cena foi proposta e ele se entregou aquele momento. Foi marcante sua emoção e satisfação em conseguir quebrar esse medo e o quanto ele pôde criar nesse plano, inclusive ressignificando a cena de início.

A dança, e em especial, a dança contemporânea, amplia as ações positivas de seus instrumentos ao corpo com deficiência, além das questões inclusivas e motoras e passando para aspectos da saúde mental e emocional. Visualizar neste trabalho a pesquisa para criação de repertórios nesses corpos serviu como enriquecimento entre os estudos como resultados positivos na área.

Contribuindo com esse resultado, Rossi e Munster (2013, p.19), falam: " [...] nos últimos cinco anos, houve a preocupação com temas que envolveram aspectos acerca da saúde, fazendo da dança um agente importante para a melhoria da qualidade de vida das pessoas com deficiência". As autoras ainda narram sobre os resultados positivos da dança para os aspectos de autoestima, comportamento e a saúde mental. 


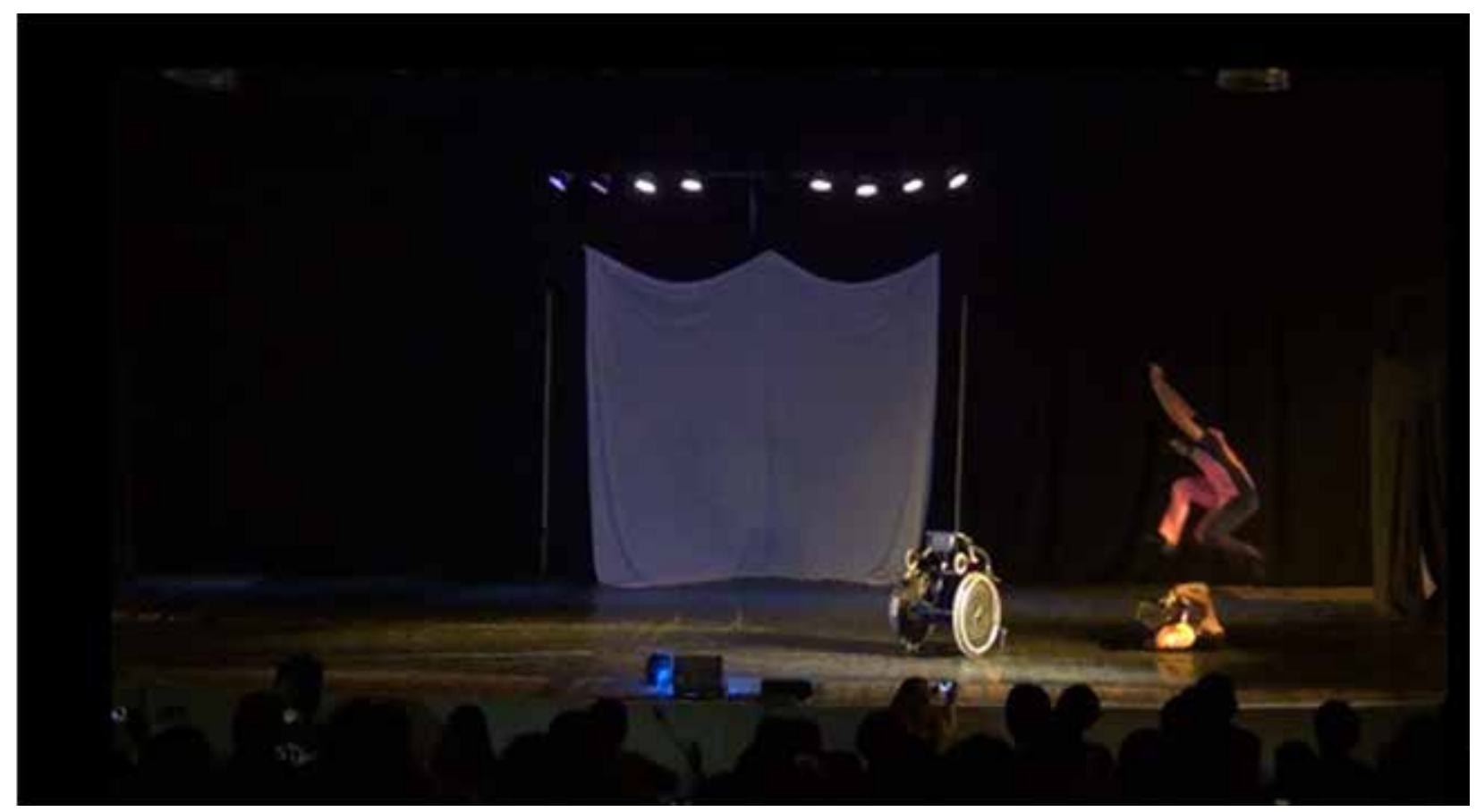

Figura 2 - Fotografia 3 - Cena em que o medo de sair da cadeira de rodas, desaparece.

Fonte: Arquivo MultiCorpo Cia de Dança. Centro de Convenções de Tucuruí, 2015.

\section{CONCLUSÃO}

O processo de criação no meio artístico requer muitas ferramentas, ações e disposição para nos lançarmos à investigação e assim visualizarmos resultados significativamente positivos entre as pessoas sem deficiência que transitam no meio social. Imaginemos então este processo entre as pessoas com deficiência, onde o princípio é saber se estas pessoas se encontram efetivamente transitando na sociedade, buscando serem vistas além de suas limitações.

A pesquisa ora apresentada resultou em contribuições positivas para o fazer dançante da pessoa com deficiência, além das questões inclusivas, propondo investigações a partir das ferramentasqueadançacontemporânea apresenta. Observamos que medos psíquicos das pessoas com deficiência foram retirados, a autoestima elevada. Os artistas envolvidos concluíram a pesquisa certos de sua capacidade de criar e recriar e com repertório amplo a partir do mergulho que fizemos em nossos corpos, independente dos rótulos de pessoas com deficiência e sem deficiência.

Sabemos que as dificuldades em transitarmos no meio artístico são profundas e elas são potencializadas aos artistas com deficiência. Buscarmos cada vez mais meios para pesquisas na área é fundamental. Precisamos de mais artistas que se lancem a estas propostas e com parceiros científicos, privados, ações da gestão pública em que tudo pode convergir para estas pesquisas, a fim de obtermos cada vez mais resultados positivos.

As experimentações foram positivas e além do esperado, por outro lado, foi constatado também que a sociedade e os próprios artistas em Tucuruí têm dificuldade em ver as pessoas com deficiência como artistas, além da chamada dança inclusiva, esta sociedade ainda os enxerga com olhos de desconfiança e acreditamos que esta visão ainda foi potencializada pelo fato de estarmos no interior do estado, onde ações na área artística quanto à produção, formação de plateia e captação de incentivos financeiros são mais difíceis.

Porém, desta pesquisa, surgiram as realizações do dever alcançado, sobre acreditarmos em nossas possibilidades de intervenção, de criação, de ressignificação em nosso corpo-sujeito. Surgiu também a ratificação de que as inquietações que surgem em nossa trajetória enquanto humanos são fundamentais para nos manterem atuantes enquanto cidadãos, artistas, e que essas ações nos levam a transcender nossas barreiras, que podem aparecer em corpos com ou sem deficiência. 


\section{REFERÊNCIAS BIBLIOGRÁFICAS}

ALBRIGHT, Ann. Moving Across Difference: Dance and Disability. Tradução de Consuelo Vallandro Barbo e Mônica Fagundes Dantas. Em: <file:///C:/Users/Rose/Downloads/37658149615-1-PB.pdf >. Acesso em 23.03.2015.

BELÉM, Elisa. Abordagens do movimento: o contato-improvisação e o toque nas práticas do estúdio Dudude Herrmann. Revista Cena Capa, 2011. Disponível em: <http://seer.ufrgs.br/ index.php/cena/article/view/20836/13126>. Acesso em 23.03.2015.

KOUDELA, Ingrid Dormien. Jogos Teatrais. São Paulo: Editora Perspectiva, 2013.

PLÁ, A. P. Projeto “Pés? - Teatro-dança para pessoas com deficiência". 2013, 52 f. Trabalho de Conclusão de Curso (Bacharel em Publicidade e Propaganda) - Faculdade de Comunicação, Universidade de Brasília, Brasília, 2013.

ROCHA, Deizi Domingues. Corpos, tempos e espaços: Descobrindo caminhos para a composição coreográfica do corpo com deficiência visual. 2010. 91 f. Monografia (Especialização em Pedagogia da Educação Física)Curso de Pós-Graduação Especialização Latu Sensu em Educação Física-Universidade Comunitária da Região de Chapecó - UNOCHAPECÓ, Chapecó, 2010. Disponível em:<http://www.uniedu.sed. sc.gov.br/wp-content/uploads/2013/10/DeiziDomingues-daRocha.pdf $>$. Acesso em 23.03.2015.

ROSSI, Patrícia; MUNSTER, Mey de Abreu Van. Dança e deficiência: uma revisão bibliográfica em teses e dissertações nacionais. Movimento, Porto Alegre, v. 19 , n. 04 , p. 181-205, out/ dez de 2013. Disponível em: <http://www. seer.ufrgs.br/index.php/Movimento/article/ view/39132/27450>. Acesso em 23.03.2015.

SOMERA, N. 0 artista com deficiência no Brasil: Arte, Inclusão Social e Campo Artístico. 2008. 163 p. Dissertação (Mestrado em Artes) - Instituto de Artes, Universidade Estadual de Campinas, Campinas, 2008.

TEIXEIRA, Ana Carolina Bezerra. Deficiência em cena: o corpo deficiente entre criações e subversões. Ensaio Geral, Edição Especial, Belém, v1, n.1, 2010.
THIOLLENT, Michel. Metodologia da pesquisaação. 11. ed. São Paulo, SP: Cortez, 2002.

TURSI, Rafael. Como dança quem não dança?. In: Congresso da ABRACE - Associação Brasileira de Pesquisa e Pós-graduação em Artes Cênicas, 7., 2012, Porto Alegre. Anais... Porto Alegre, 2012.

\section{SOBRE A AUTORA}

Roseane Monteiro dos Santos é Mestra em Ciência da Motricidade Humana pela Universidade Castelo Branco (UCB-RJ). Especialista em Pedagogia do Movimento Humano pela Universidade do Estado do Pará (UEPA). Licenciada e Bacharel em Educação Física pela Universidade do Estado do Pará (UEPA) CREF 003865 G/PA. É professora Assistente do Curso de Educação Física e Enfermagem do Campus XIII da Universidade do Estado do Pará. É professora Nível Superior B da Prefeitura Municipal de Tucuruí. Pesquisadora da área do movimento. É bailarina e coreógrafa profissional DRT n) 113/PA. Tem experiência na área de Educação Física escolar, Motricidade Humana com foco em crianças, idosos e pessoas com deficiência, atuando principalmente nos seguintes temas: Educação Física; Dança/Educação/Performance, Crescimento Físico e Estado Nutricional, Atividade Física no Envelhecimento Humano; Dança para Pessoas com Deficiência. É idealizadora e coordenadora do Tucuruí em Dança. É diretora Artística do Studio de Dança Rose Monteiro. É idealizadora e diretora artística da MultiCorpo Cia de Dança. É idealizadora da Tucuruí Cia Municipal de Dança e da Cia Parafolclórica Municipal de Tucuruí. Ocupou o cargo de Diretora Executiva de Cultura da Prefeitura Municipal de Tucuruí em duas administrações distintas. 